\title{
アルギン酸による印象時の氣泡発生及び模型への 影響について
}

\section{2. 印象材の形式から見た気泡の発生状態並び に気泡発生の原因について}

前回の報告で，石济粒の発生がわれわれの行い得る印 象前の処置でどのように変化するかを㴶験したが，今回 は印象材の型式による差及び気泡発生の原因について多 少の知見を得たので報告する。

\section{A. 印象材の形式からみた気泡 発生の状態}

\section{実験材料及び方法}

印象材は粉末型式ベイスト型式のものをおのおの 2 種つつ選び（以下粉末型式のものはWA，WT，ヘイス 卜型式のものは，PA，PL と仮称する）所定の使用法 から考え一罘につき炊の様な配合とした。

$$
\begin{aligned}
& \mathrm{WA} \text { - 粉末 } 24 \mathrm{~g} \text { 水 } 50 \mathrm{cc} \\
& \mathrm{WT} \text { - 粉末 } 20 \mathrm{~g} \text { 水 } 50 \mathrm{cc} \\
& \text { PAーペイス } 60 \mathrm{~g} \text { 石数 } 13 \mathrm{~g} \\
& \text { PLーペスト60g 石篦 } 13 \mathrm{~g}
\end{aligned}
$$

上記の制合で各々を練和し，その粘䅕度を内腿的に榴 祭しWAが最も高く，PA，PLがこれに次ぎ，WTが最 も低いように思われた。

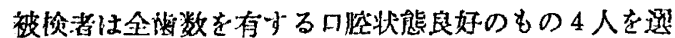
び，裴 1 に示すように印像材と組合せ，印像忉全部に被

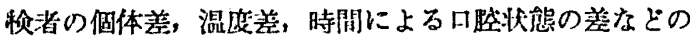
姡らつきがなくなるよう心がけた。

また，印象前の処置として简监なスケーリングを行 い，綿花で不梁物を取除き，水でうがいを行い，面処置 は行わずに印象し，計测方法などは前回と同栐とした。

\section{実験成績及び検討}

被検印象材を通じ，最も石被粓発生度の掵いものは，

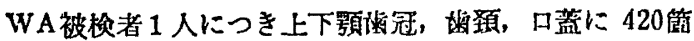

\begin{tabular}{|c|c|c|c|c|c|c|}
\hline 月日 被松兠 & A & B & C & D & 水温 & 室温 \\
\hline 6 月 16 日 & WA & WT & PA & PL & $19.0^{\circ} \mathrm{C}$ & $23.0^{\circ} \mathrm{C}$ \\
\hline 17 日 & PL & WA & WT & PA & 17.5 & 21.0 \\
\hline 18 日 & PA & PL & WA & WT & 17.5 & 21.0 \\
\hline 18 日 & WT & PA & PL & WA & 18.0 & 22.0 \\
\hline
\end{tabular}

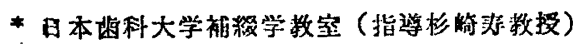

松尾悦 郎 ${ }^{*}$ 長屋圭一

表 1 印缘材と被损者の組合女

欣いで PA 355箇, WT 310䇫, PL 309䉯で殆んど同数

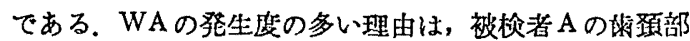
に発生した $1 \mathrm{~mm}$ 以下のものが原因と考えられ，粉末型 式とペイスト型式では石臂粒の発生には殆んど差を認め ないが，石霄粒の大きさからみるとべイスト型式のもの

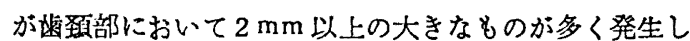
ているが，その他には差を認めなかつた。

また，WA，PA は製造会社が同一であり他のものと 比校して発生数のやや多いのは粘稑度に関係することは 非常に大きいが，その他に気泡発生に関係する因子が多 く含まれるものと考えられる。

B. 気泡発生の原因について

どうしてこのような気泡或いは石酶粒が生ずるかを考 える時, 拯伴時にアルギン酸内に混入した気泡が印象時 に表面に現われるためと，印象材と粘瞙の間の空気が逃 げ切れずに残るためとの何れかに思われ，以下記述する 数理の実臨を試みこれを追究してみた。

\section{実験方法とその結果}

\section{実 験 1}

擢件時にアルギン酸内に湿入した気泡を取り除いて印 像を行うべく考え，デシケーター中に撚伴したアルギン 酸を入れ，真空ボンプで引き減圧下に放置してみた。粉 
末 $12 \mathrm{~g}$ ，水 $25 \mathrm{cc}$ を 1 分門混和し時計皿に盛りデラータ

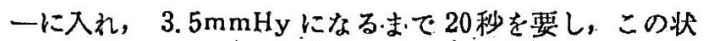
態で30秒継統，直ちに常压に质した，結果は娍圧の度が 強くなるに従い,アルギン酸は非常に璐張し，小数の気 泡が浮上して来るのが認められたが，硬化後その切断面 を短察すると，材料内の気泡は脚大し多数存在して怪石 状をなしており，減压下においてもこの状俧であるか ら，一度材料内に混入した気泡を取除くことは非常に困 難なことと思われる.(図1)

图 1

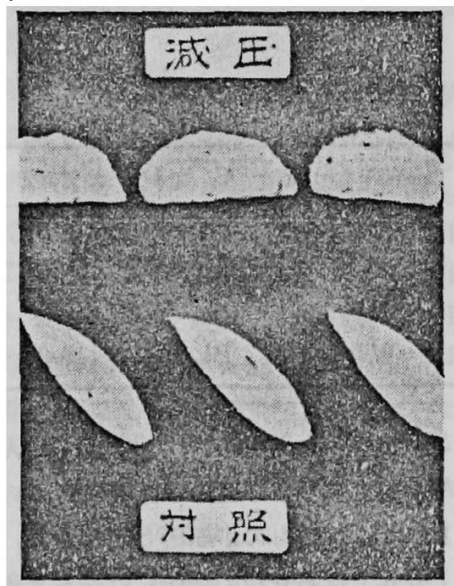

\section{実 験 2}

金属製リング $\left(7.0 \mathrm{~cm}^{2} \times 3.8 \mathrm{~cm}\right)$ に㹂伴したアルギ ン酸（粉米 $12 \mathrm{~g}$ 水 $25 \mathrm{cc}$ ）を入れ，その表面に人工的に凹 みを 2 つ作り，1つは薄く表面をアルギン酸で包み，気 泡が材料内に入つている状態に，他の1つはそのまま で，おのおの表面を平らな板で被い，加臬を $3 \mathrm{~g} / \mathrm{cm}^{2}$,

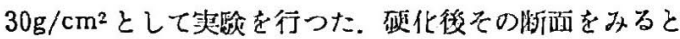
凹みとしたものはすへてて㸚泡となつており，咑料内のも のは1つも装預に裴われなかつた。

图 2

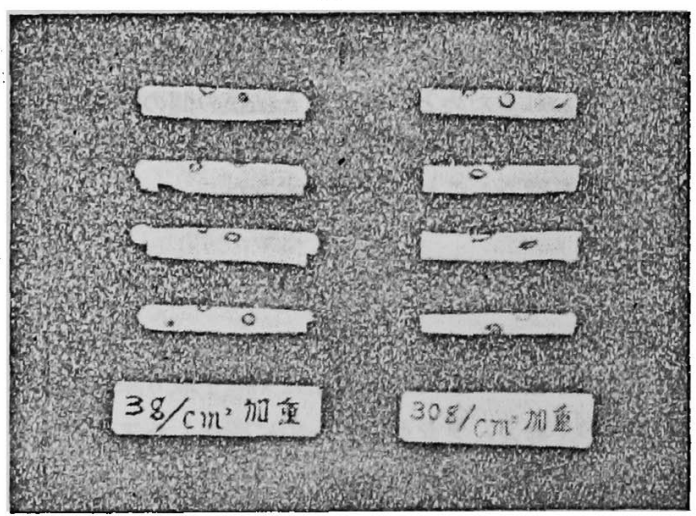

実 駼 3

..トレーに盘つたアルギン酸の表面に;. . インクで色付け したアルギン酸を $1 〜 2 \mathrm{~mm}$ の厚さで一栐に㳂り印象: し，硬化後トレーかから戊ずて矢状位断，額面位断で袏 祭する将，印象䤄に沿つてほ济同一の原さで色付けした アルギン酸が存在し，色付けしないものが表面に表われ た部位は登胃できなかつた。

图 3

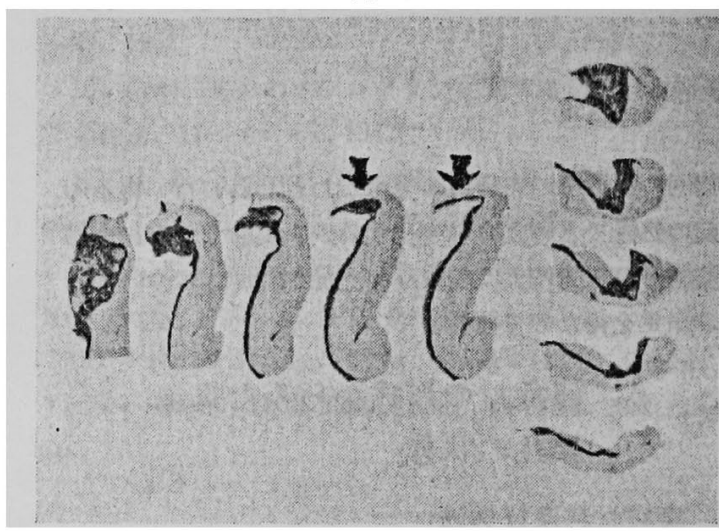

なお，上記の实験と同㥞の才法で，印爱洔にトレーを 可成り烈しく上下左右に姐しした場合は，前遴部に色付け しないアルギン酸が表われている以外は前実験と同粎の. 結果であり，これはトレーを趿かす時に前爾切端が支点 となつたためと考えられる。（図3，4 の矢印部を比較）

图 4

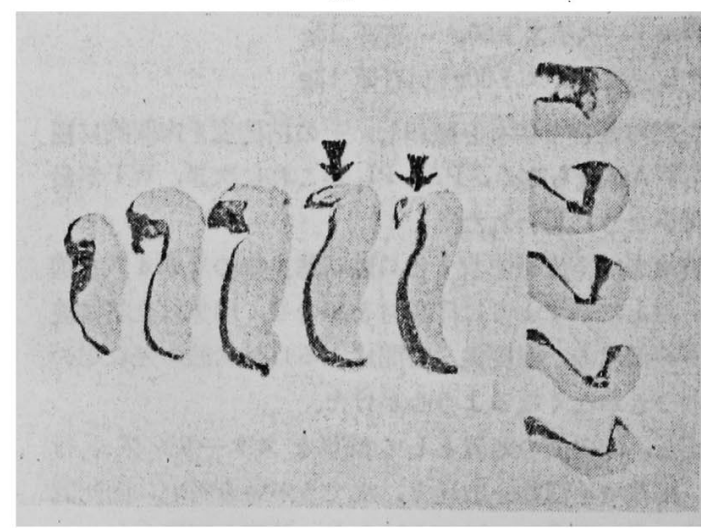

実 駼 4

晛伴したアルギン酸をトレーに盛り，筆でインクを図

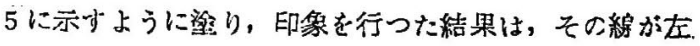
右㑷後に拡つた状態となつて現われてくる。

実 験 5

表 1 に用いた被検者につきおのおの印像材WA を使用 
図 5

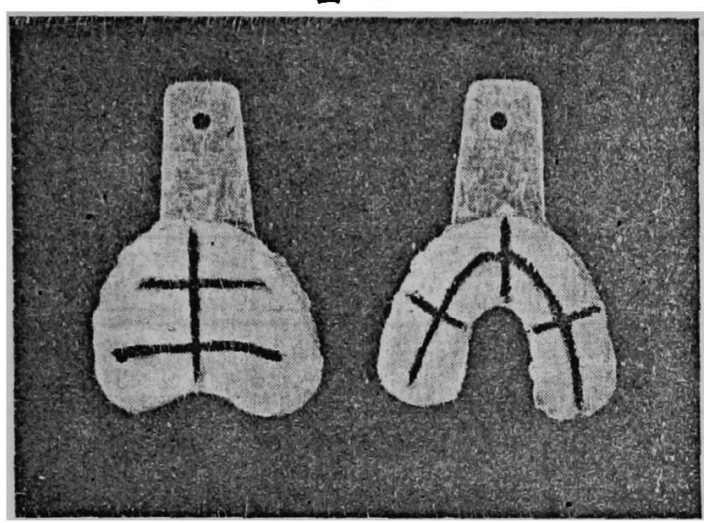

しスナッブ印象を取り，模型上でモデリングで各個トレ 一を製作し, 再ひ WA (粉末 $12 \mathrm{~g}$ 水 $25 \mathrm{cc}$ ) で印象を取り 石高粒数を比較してみた。

結果は $2 \mathrm{~mm}$ 以上の大きな不高粒を発生することはな
図 6

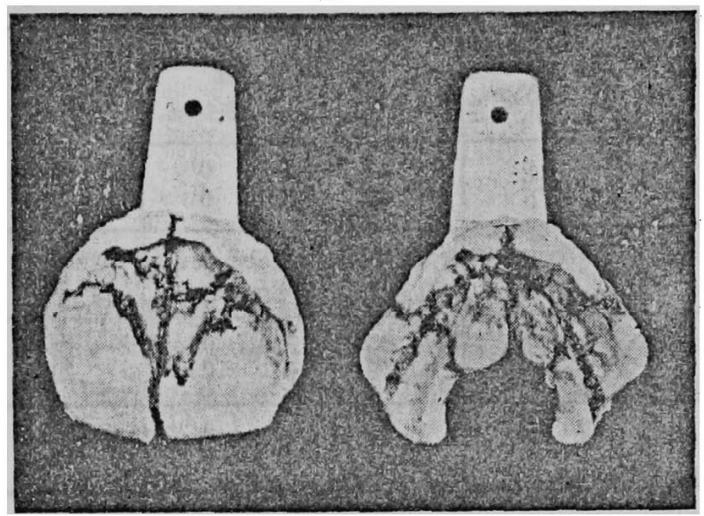

く, 1〜2 $\mathrm{mm}$ のものが少数生じる外は小さなものばか りで, これも非常に減少しており肉眼的には可成優秀な 成絀を得た。

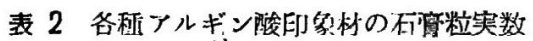

\begin{tabular}{|c|c|c|c|c|c|c|c|c|c|c|c|}
\hline 印 & 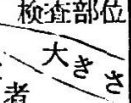 & $\begin{array}{r}\text { 歯 } \\
0 \sim 1\end{array}$ & $1 \sim 2$ & $\begin{array}{l}\text { 就: } \\
2 \sim \infty\end{array}$ & $\begin{array}{r}\text { 㧘 } \\
0 \sim 1\end{array}$ & $1 \sim 2$ & $\begin{array}{l}\text { 顼 } \\
2 \sim \infty\end{array}$ & $\begin{array}{r}\text { 口 } \\
0 \sim 1\end{array}$ & $1 \sim 2$ & $\begin{array}{l}\text { 搵 } \\
2 \sim \infty\end{array}$ & 総 \\
\hline \multirow{4}{*}{ WA } & A $\frac{5}{F}$ & $\begin{array}{l}75 \\
25\end{array}$ & $\begin{array}{l}7 \\
4\end{array}$ & $\begin{array}{l}4 \\
1\end{array}$ & $\begin{array}{r}307 \\
89\end{array}$ & $\begin{array}{l}8 \\
9\end{array}$ & $\begin{array}{l}3 \\
4\end{array}$ & 55 & 6 & 4 & $\begin{array}{l}469 \\
132\end{array}$ \\
\hline & B 攴 & $\begin{array}{l}5.3 \\
31\end{array}$ & $\begin{array}{l}5 \\
4\end{array}$ & $\begin{array}{l}1 \\
2\end{array}$ & $\begin{array}{r}128 \\
83\end{array}$ & $\begin{array}{l}9 \\
3\end{array}$ & $\begin{array}{l}6 \\
2\end{array}$ & 45 & 4 & 4 & $\begin{array}{l}255 \\
125\end{array}$ \\
\hline & C $\frac{\text { 上 }}{\mathrm{F}}$ & $\begin{array}{l}30 \\
24\end{array}$ & $\begin{array}{l}3 \\
3\end{array}$ & $\begin{array}{l}4 \\
3\end{array}$ & $\begin{array}{l}71 \\
98\end{array}$ & $\begin{array}{r}7 \\
12\end{array}$ & $\begin{array}{l}6 \\
5\end{array}$ & 46 & 5 & 7 & $\begin{array}{l}179 \\
145\end{array}$ \\
\hline & D & $\begin{array}{l}36 \\
23\end{array}$ & $\begin{array}{l}5 \\
3\end{array}$ & $\begin{array}{l}3 \\
1\end{array}$ & $\begin{array}{l}96 \\
87\end{array}$ & $\begin{array}{l}9 \\
6\end{array}$ & $\begin{array}{l}4 \\
4\end{array}$ & 22 & 3 & 2 & $\begin{array}{l}180 \\
124\end{array}$ \\
\hline \multirow{4}{*}{ WT } & A & $\begin{array}{l}40 \\
16\end{array}$ & $\begin{array}{l}2 \\
0\end{array}$ & $\begin{array}{l}3 \\
3\end{array}$ & $\begin{array}{r}123 \\
79\end{array}$ & $\begin{array}{l}4 \\
8\end{array}$ & $\begin{array}{l}2 \\
1\end{array}$ & 23 & 5 & 3 & $\begin{array}{l}205 \\
107\end{array}$ \\
\hline & $\mathrm{B} \frac{\mathrm{t}}{\mathrm{F}}$ & $\begin{array}{l}37 \\
22\end{array}$ & $\begin{array}{l}7 \\
9\end{array}$ & $\begin{array}{l}3 \\
2\end{array}$ & $\begin{array}{r}175 \\
87\end{array}$ & $\begin{array}{l}7 \\
4\end{array}$ & $\begin{array}{l}4 \\
2\end{array}$ & 19 & 3 & 2 & $\begin{array}{l}257 \\
126\end{array}$ \\
\hline & C 贞 & $\begin{array}{l}48 \\
13\end{array}$ & $\begin{array}{l}4 \\
1\end{array}$ & $\begin{array}{l}3 \\
2\end{array}$ & $\begin{array}{l}84 \\
78\end{array}$ & $\begin{array}{r}6 \\
10\end{array}$ & $\begin{array}{l}1 \\
5\end{array}$ & 28 & 6 & 4 & $\begin{array}{l}184 \\
109\end{array}$ \\
\hline & $D$ 占: & $\begin{array}{l}29 \\
15\end{array}$ & $\begin{array}{l}2 \\
2\end{array}$ & $\begin{array}{l}3 \\
1\end{array}$ & $\begin{array}{l}69 \\
98\end{array}$ & $\begin{array}{l}6 \\
8\end{array}$ & $\begin{array}{l}1 \\
0\end{array}$ & 13 & 4 & 2 & $\begin{array}{l}129 \\
124\end{array}$ \\
\hline \multirow{4}{*}{ P A } & A $\frac{1}{F}$ & $\begin{array}{l}48 \\
36\end{array}$ & $\begin{array}{r}10 \\
2\end{array}$ & $\begin{array}{l}3 \\
2\end{array}$ & $\begin{array}{l}124 \\
110\end{array}$ & $\begin{array}{l}8 \\
6\end{array}$ & $\begin{array}{l}3 \\
4\end{array}$ & 41 & 5 & 3 & $\begin{array}{l}245 \\
160\end{array}$ \\
\hline & $B \frac{5}{F}$ & $\begin{array}{l}40 \\
25\end{array}$ & $\begin{array}{l}9 \\
3\end{array}$ & $\begin{array}{l}5 \\
2\end{array}$ & $\begin{array}{r}101 \\
98\end{array}$ & $\begin{array}{l}8 \\
7\end{array}$ & $\begin{array}{l}8 \\
3\end{array}$ & 26 & 5 & 4 & $\begin{array}{l}233 \\
138 \\
\end{array}$ \\
\hline & c 卡 & $\begin{array}{l}41 \\
30\end{array}$ & $\begin{array}{l}4 \\
4\end{array}$ & $\begin{array}{l}5 \\
0\end{array}$ & $\begin{array}{r}58 \\
123\end{array}$ & $\begin{array}{l}3 \\
7\end{array}$ & $\begin{array}{r}7 \\
11\end{array}$ & 43 & 8 & 8 & $\begin{array}{l}177 \\
175\end{array}$ \\
\hline & D 卡 & $\begin{array}{l}47 \\
26\end{array}$ & $\begin{array}{l}3 \\
2\end{array}$ & $\begin{array}{l}4 \\
1\end{array}$ & $\begin{array}{l}88 \\
82\end{array}$ & $\begin{array}{l}12 \\
10\end{array}$ & $\begin{array}{l}6 \\
5\end{array}$ & 17 & 5 & 2 & $\begin{array}{l}184 \\
126\end{array}$ \\
\hline \multirow{4}{*}{ P L } & A $\frac{5}{F}$ & $\begin{array}{l}27 \\
38\end{array}$ & 5 & $\begin{array}{l}3 \\
0\end{array}$ & $\begin{array}{r}68 \\
133\end{array}$ & $\begin{array}{l}6 \\
5\end{array}$ & $\begin{array}{l}8 \\
4\end{array}$ & 21 & 3 & 2 & $\begin{array}{l}143 \\
184\end{array}$ \\
\hline & B 占 & $\begin{array}{l}48 \\
21\end{array}$ & $\begin{array}{l}4 \\
4\end{array}$ & $\begin{array}{l}3 \\
0\end{array}$ & $\begin{array}{r}154 \\
69\end{array}$ & $\begin{array}{l}8 \\
4\end{array}$ & $\begin{array}{l}4 \\
5\end{array}$ & $\overline{38}$ & 2 & 5 & $\begin{array}{l}266 \\
103\end{array}$ \\
\hline & $c \frac{1}{F}$ & $\begin{array}{l}25 \\
19\end{array}$ & 4 & $\begin{array}{l}5 \\
3\end{array}$ & $\begin{array}{l}84 \\
71\end{array}$ & $\begin{array}{l}3 \\
7\end{array}$ & $\begin{array}{l}3 \\
2\end{array}$ & 38 & 8 & 5 & $\begin{array}{l}175 \\
106\end{array}$ \\
\hline & $D \frac{5}{下}$ & $\begin{array}{l}26 \\
35\end{array}$ & $\begin{array}{l}5 \\
2\end{array}$ & $\begin{array}{l}2 \\
1\end{array}$ & $\begin{array}{l}63 \\
71\end{array}$ & $\begin{array}{r}22 \\
6\end{array}$ & $\begin{array}{l}6 \\
0\end{array}$ & 10 & 6 & 4 & $\begin{array}{l}144 \\
115\end{array}$ \\
\hline
\end{tabular}


表 3 各個トレーを用いた垐合の不解粒实数

\begin{tabular}{|c|c|c|c|c|c|c|c|c|c|c|c|c|}
\hline 被梌 & 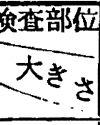 & $\begin{array}{r}\text { 药 } \\
0 \sim 1\end{array}$ & $1 \sim 2$ & $\begin{array}{l}\text { 冠 } \\
2 \sim \infty\end{array}$ & $\begin{array}{r}\text { 歯 } \\
0 \sim 1\end{array}$ & $1 \sim 2$ & $\begin{array}{l}\text { 頝 } \\
2 \sim \infty\end{array}$ & $\begin{array}{r}\text { 口 } \\
0 \sim 1 \\
\end{array}$ & $1 \sim 2$ & $\begin{array}{l}\text { 䔐 } \\
2 \sim \infty\end{array}$ & 䋓 & 計 \\
\hline A & $\frac{5}{F}$ & $\begin{array}{l}40 \\
22\end{array}$ & $\begin{array}{l}2 \\
2\end{array}$ & $\begin{array}{l}0 \\
0\end{array}$ & $\begin{array}{l}30 \\
24\end{array}$ & $\begin{array}{l}5 \\
1\end{array}$ & $\begin{array}{l}1 \\
0\end{array}$ & 12 & 2 & 0 & & $\begin{array}{l}92 \\
49 \\
\end{array}$ \\
\hline B & 上下 & $\begin{array}{l}29 \\
17\end{array}$ & $\begin{array}{l}2 \\
0\end{array}$ & $\begin{array}{l}0 \\
0\end{array}$ & $\begin{array}{l}60 \\
18\end{array}$ & $\begin{array}{l}1 \\
1\end{array}$ & $\begin{array}{l}0 \\
0\end{array}$ & 18 & 3 & 0 & & $\begin{array}{r}113 \\
36\end{array}$ \\
\hline C & 卡 & $\begin{array}{l}33 \\
15\end{array}$ & $\begin{array}{l}3 \\
0\end{array}$ & $\begin{array}{l}0 \\
0\end{array}$ & $\begin{array}{l}64 \\
21\end{array}$ & $\begin{array}{l}3 \\
1\end{array}$ & $\begin{array}{l}0 \\
0\end{array}$ & 27 & 3 & 0 & & $\begin{array}{r}133 \\
37\end{array}$ \\
\hline D & $\frac{上}{F}$ & $\begin{array}{r}11 \\
2\end{array}$ & $\begin{array}{l}1 \\
0\end{array}$ & $\begin{array}{l}0 \\
0\end{array}$ & $\begin{array}{r}25 \\
6\end{array}$ & $\begin{array}{l}0 \\
0\end{array}$ & $\begin{array}{l}0 \\
0\end{array}$ & 3 & 2 & 0 & & $\begin{array}{r}42 \\
8\end{array}$ \\
\hline
\end{tabular}

\section{考察。}

実跧 1では，減圧下においても気泡は除去し得ないこ とが判明し，印象洔に加圧しても内部の父泡が浮上ずる ことは不可能と思われ，更に印缘洔の材料の移政を莙え

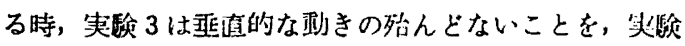
4 は平面的な勘きが烈しいものでなく全体に抎がること

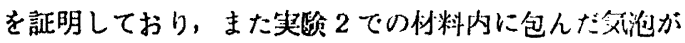
王の軽重によつても表面に現われないことから，筧件時 に材料队に湜入した気泡が原因となることは㱠んと完全 に否定できる。

そこで，印象と粘膜面の間の逃汗切えない空氮が原因 となると思われるが，これを直接証明する良い実験方法 が見当らないので，㳄に述へる程々の可实に従つて究明 を試みた，笑監 5 におけるように各個トレーを製作し， 空気が平等に逃げるように陚みた結果は，大きな気泡は 殆んどな，小さな父泡は若干依然として存在するが各 個トレーの効果は認められた。

実験 2 で凹みとしたものがすへてて父泡となつているこ とは, アルギン酸の面の小さな山凸が気泡となり, 前回 の報告で面処置したものの気沱の発生が少くなつている ことは、この処置でアルギン酸の小さな约出㴥される

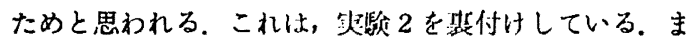

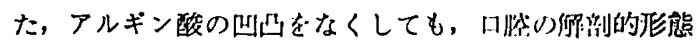

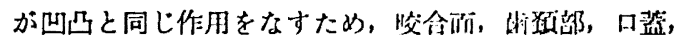

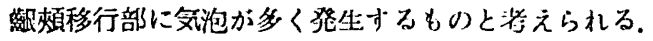

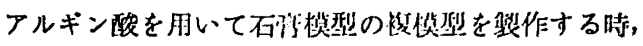
複模型には石斿粒が登坐せず,レジン榄型の被模型製作

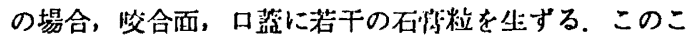
とは生体における場合と比較し，跟梧移行，口蓝後方か
ら空文が逃げることと，石高模型に山或程度の通気性の あることが考えられる。

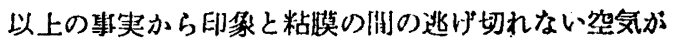
主因をなすこと怡んど俱りのないものと考える.

$$
\text { 尘と好 }
$$

1. 粉末型式とヘイスト型式では，慔型面に現われる石 痛粒数に大きな差を認めない。

2. ヘイイスト型式のものは, 粉沫型式のものより宩䅡に おいて $2 \mathrm{~mm}$ 以上の大きな石旃粒を多く笔生する.

3. 提伴侍にアルギン酸内に混入した気泡が印象洔に表 面に现引代攽泡となることはなく，気泡発生の原因は印 偣と粘膜㮌の間の逃げ切れない筀気によるものと考え 万.

稿を終るに当つて，御指導，御敃閲を赐つた杉崎教授 に樑诘なる感謝の等を表わし，被检者となり御塯力下さ つた学生諸氏に御礼申し上げる。

\section{文献}

1) Hedegard B., Nyquist. G.: Dental Abstracts Vol. 1, No. 10, 1956.

2) Saizar P.: Dental Abstracts Vol. 1, No. 10, 1956.

3) Klark R. J. : J. Pros. Den. Vol. 7, No. 2, 1957.

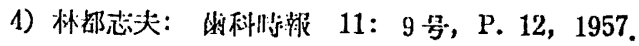

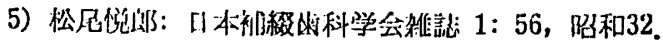

6）富同健太郎：幽科時報 7: 185, 昭和 28 。 